\title{
MAXIMIZAÇÃO DA PRODUÇÃO DE ENDO XILANASE DE Cryptococcus laurentii
}

\author{
D. M. OTERO ${ }^{1}$, C. L. CADAVAL ${ }^{1}$, L.M. TEXEIRA ${ }^{1}$, A.R.C. BRAGA ${ }^{1}$, C. ROSA ${ }^{2}$, S.J.KALIL ${ }^{1}$ \\ ${ }^{1}$ Universidade Federal do Rio Grande, Escola de Química e Alimentos \\ ${ }^{2}$ Universidade Federal de Minas Gerais, Departamento de Microbiologia \\ E-mail para contato: deborah.m.otero@gmail.com
}

\begin{abstract}
RESUMO - A endo $\beta-1,4$ xilanase, principal enzima do complexo xilanolítico, hidrolisa aleatoriamente ligações $\beta-1,4$ da cadeia de hemicelulose e o interesse no seu estudo vem sendo estimulado pela sua aplicação em rações animais e no branqueamento de papel. Diante da importância da aplicação das xilanases é importante avaliar condições que aumentem a produção dessas enzimas a fim de tornar sua utilização comercial menos restrita. Neste trabalho foi realizada a produção de endo xilanase utilizando a levedura Cryptococcus laurentii. Cultivos submersos foram realizados, avaliando os componentes do meio de cultivo, através do uso de planejamento experimental fracionário, visando uma maior atividade da enzima. Os cultivos foram mantidos a $30^{\circ} \mathrm{C}, 150 \mathrm{rpm}$ por 96 horas. A produção inicial foi de $3,4 \mathrm{U} / \mathrm{mL}$, sendo que esta, após os experimentos, teve um incremento cerca de $60 \%$, onde a atividade máxima foi de $5,5 \mathrm{U} / \mathrm{mL}$.
\end{abstract}

\section{INTRODUÇÃO}

As endo $\beta$ 1,4 xilanases (EC 3.2.1.8) são enzimas extracelulares que catalisam a hidrólise de substratos que possuem ligações do tipo $\beta 1,4$, produzidas principalmente por bactérias (Nagar, 2010, Rajoplan, 2013) e bolores (Ang, 2013; Moreira, 2013). A xilana é o principal representante dentre os substratos susceptíveis ao ataque hidrolítico das xilanases. Este polímero é o principal componente da hemicelulose e é composto por resíduos de $\beta$-xilopiranose, unidos por ligações $\beta 1,4$ com graus de substituições variáveis em suas cadeias laterais. Os produtos da hidrólise das xilanas são monômeros D-xilose e xilo-oligossacarídeos de diferentes tamanhos (Heck, 2006; Jänis, 2007). 
As xilanases são um grupo de enzimas utilizadas nas mais diversas aplicações, destacando-se especialmente na indústria de polpa e papel (branqueamento de celulose), biocombustíveis (produção de etanol), no setor de alimentos (clarificação de sucos e vinhos e panificação) e em rações animais (melhorando a digestibilidade e aumentando o valor nutricional de rações) (Lopes, 2010).

O desenvolvimento e aprimoramento de tecnologias visando a produção de xilanases com características bioquímicas adequadas à aplicação industrial têm sido o objetivo de muitos trabalhos. Além disso, a necessidade crescente da otimização de produtos e processos, minimizando custos e tempo, maximizando rendimento, produtividade e qualidade de bioprodutos, dentre outros objetivos, tem levado profissionais de diferentes formações a buscarem técnicas sistemáticas de planejamento de experimentos (Rodrigues e Iemma, 2005; Lopes, 2010).

Entre os parâmetros em bioprocessos que podem afetar a atividade e produtividade das xilanases durante a fermentação incluem-se: o pH, a temperatura, fonte de carbono orgânico e inorgânico e fonte de nitrogênio (Kulkarni et al., 1999; Haltrich et al., 1996, Li et al., 2007). Esses fatores têm demonstrado influenciar a produtividade da xilanase em vários estudos, entretanto, as condições ótimas são únicas para cada micro-organismo e processo, por isso a necessidade de estudar cada componente em questão.

Atualmente muito tem se estudado sobre a produção de xilanase a partir de fungos filamentosos e bactérias, porém a produção por leveduras não é muito citada (Motta, 2008; Scorzetti, 2000) mesmo sabendo-se que existem leveduras que são produtoras desta enzima naturalmente. Sendo assim, o objetivo deste trabalho foi estudar a influência de alguns parâmetros sob a atividade de endo xilanases, produzidas por Cryptococcus laurentii, buscando assim uma maior atividade.

\section{MATERIAL E MÉTODOS}

\subsection{Micro-organismo}

A levedura utilizada neste trabalho foi isolada anteriormente por Otero (2012) e identificada como Cryptococcus laurentii. A levedura foi conservada em ágar GYMP inclinado (composto por glicose $(2 \%)$, extrato de levedura $(0,5 \%)$, extrato de malte $(1,0 \%)$, fosfato sódico monobásico $(0,2 \%)$ e ágar $(2 \%)$ ) e mantida sob refrigeração à $4{ }^{\circ} \mathrm{C}$.

\subsection{Seleção das variáveis estudadas}

As variáveis envolvidas no cultivo da levedura para produção enzimática foram: $\mathrm{pH}$, concentração de peptona, extrato de levedura, fosfato monobásico, sulfato de amônio e de xilana. Para a realização dos cultivos foram fixados a temperatura em $30^{\circ} \mathrm{C}$ e a agitação do meio em 
$150 \mathrm{rpm}$ bem como a concentração de sulfato de magnésio $\left(0,1\right.$ g. $\left.\mathrm{L}^{-1}\right)$. Um planejamento fracionário $2^{6-2}$ foi realizado, totalizando vinte ensaios.

\subsection{Cultivo da levedura para produção de xilanases}

O pré-inóculo foi realizado transferindo a massa celular da superfície do ágar inclinado GYMP para tubos de ensaio contendo $9 \mathrm{~mL}$ do meio complexo $\left(10 \mathrm{~g} . \mathrm{L}^{-1}\right.$ xilana de Beechwood, 3 g.L ${ }^{-1}$ extrato de levedura, 7 g.L $\mathrm{L}^{-1} \mathrm{KH}_{2} \mathrm{PO}_{4}, 2$ g.L ${ }^{-1} \mathrm{~K}_{2} \mathrm{HPO}_{4}, 0,1$ g.L ${ }^{-1} \mathrm{MgSO}_{4} .7 \mathrm{H}_{2} \mathrm{O}, 1$ g.L. ${ }^{-1}$ $\left(\mathrm{NH}_{4}\right)_{2} \mathrm{SO}_{4}$ e 5 g.L $\mathrm{L}^{-1}$ peptona) com pH ajustado em 6,0 sendo incubado durante 24 horas a temperatura de $30^{\circ} \mathrm{C}$. Para o inóculo foi transferido o volume do pré inóculo, para erlenmeyers contendo $150 \mathrm{~mL}$ de meio sendo mantidos durante 48 horas a $30^{\circ} \mathrm{C}$ sob agitação de $150 \mathrm{rpm}$ em agitador orbital rotatório (Motta, 2008). Para iniciar os cultivos, o inóculo foi padronizado usando

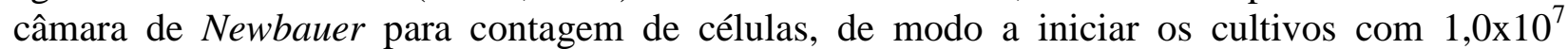
célula. $\mathrm{mL}^{-1}$. Os cultivos foram realizados em frascos erlenmeyers aletados de $500 \mathrm{ml}$ contendo $135 \mathrm{~mL}$ de meio (cada ensaio apresenta diferentes concentrações dos componentes do meio, conforme tabela 1) mantidos em agitador orbital rotatório durante 96 horas a $30^{\circ} \mathrm{C}$ sob agitação de $150 \mathrm{rpm}$. Foram coletadas amostras ao longo de cada cultivo para realizar análises em triplicata da atividade enzimática de endo xilanases.

Tabela 1: Níveis das variáveis utilizadas no planejamento fatorial fracionário $2^{6-2}$

\begin{tabular}{cccc}
\hline Variáveis & Nível -1 & Nível 0 & Nível +1 \\
\hline $\mathrm{pH}$ & 5 & 6 & 7 \\
Xilana $\left(\mathrm{g} . \mathrm{L}^{-1}\right)$ & 5 & 12,5 & 20 \\
Extrato de levedura & 1 & 3 & 5 \\
Peptona $\left(\mathrm{g} . \mathrm{L}^{-1}\right)$ & 1 & 3,5 & 6 \\
Fosfato monobásico $\left(\mathrm{g} . \mathrm{L}^{-1}\right)$ & 0 & 3,5 & 7 \\
Sulfato $\left(\mathrm{g} . \mathrm{L}^{-1}\right)$ & 1 & 3 & 5 \\
\hline
\end{tabular}

\subsection{Métodos analíticos}

\subsubsection{Determinação da atividade enzimática}

A atividade de endo xilanase foi determinada utilizando $0,9 \mathrm{~mL}$ de solução de xilana $1 \%$ e $0,1 \mathrm{~mL}$ de extrato enzimático bruto (meio bioprocessado livre de células). A reação foi mantida durante 5 minutos na temperatura de $50^{\circ} \mathrm{C}$ (Bailey, 1992). Sendo realizada a leitura em espectrofotômetro a $540 \mathrm{~nm}$ (Miller, 1959).

\section{RESULTADOS E DISCUSSÃO}

A levedura Cryptococcus laurentii, isolada de chicória por Otero (2012) produziu xilanases, através de cultivos submersos utilizando meio de cultura complexo, com atividade de 3,4 U.mL ${ }^{-1}$, em 


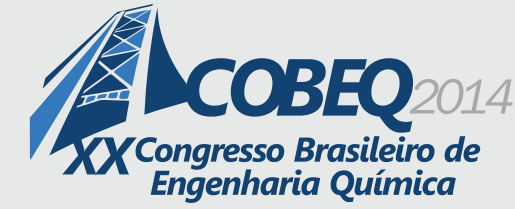

19 a 22 de outubro de 2014

Florianópolis/SC

36 horas de cultivo conforme apresentado na Figura 1. A Tabela 2 apresenta as atividades máximas alcançadas para cada ensaio realizado do planejamento fatorial $2^{6-2}$ e as mesmas foram utilizadas para realizar a análise dos efeitos da concentração dos componentes do meio de cultura e do $\mathrm{pH}$ sobre sua produção. As atividades enzimáticas variaram de 1,1 a 5,5 U.mL ${ }^{-1}$. A máxima atividade foi de 5,5 U.mL $L^{-1}$ e a mesma foi alcançada no ensaio 8 que apresentou as seguintes condições: $\mathrm{pH}$ inicial 7 , concentração de 6 g. $\mathrm{L}^{-1}$ de peptona, 20 g.L $\mathrm{L}^{-1}$ de xilana, sem a adição de fosfato potássio monobásico, 5 g. $\mathrm{L}^{-1}$ de sulfato de amônio, 1 g. $\mathrm{L}^{-1}$ de peptona e 0,1 g. $\mathrm{L}^{-1}$ de sulfato de magnésio. $\mathrm{O}$ pico da atividade enzimática nesse ensaio foi em 48 horas de cultivo, conforme apresentado na Figura 2.

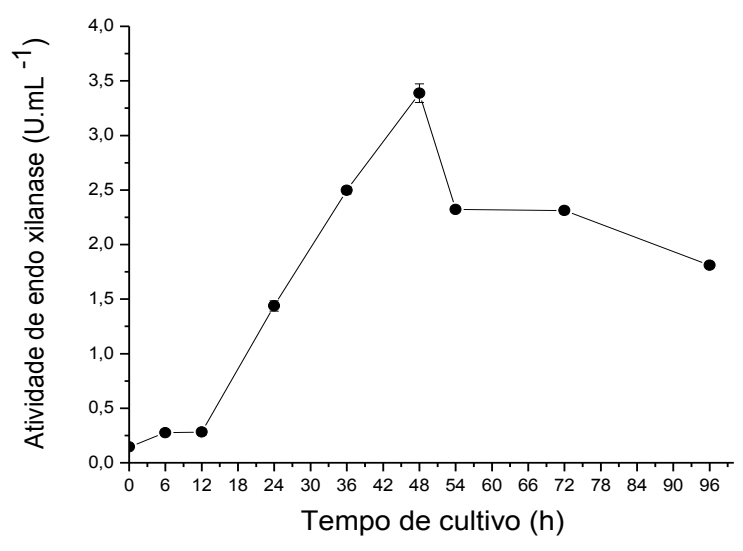

Figura 1: Acompanhamento da atividade de endo xilanases produzida por Cryptococcus laurentii ao longo de 96 horas de cultivo em meio complexo.

Tabela 2: Matriz do planejamento experimental fracionário $2^{6-2}$ (16 ensaios e 4 pontos centrais), valores codificados e reais

\begin{tabular}{|c|c|c|c|c|c|c|c|}
\hline Ensaios & $\mathrm{pH}$ & $\begin{array}{l}\text { Peptona } \\
\left(\mathrm{g} \cdot \mathrm{L}^{-1}\right)\end{array}$ & $\begin{array}{l}\text { Xilana } \\
\left(\mathrm{g} . \mathrm{L}^{-1}\right)\end{array}$ & $\begin{array}{l}\text { Fosfato } \\
\left(\mathrm{g} . \mathrm{L}^{-1}\right)\end{array}$ & $\begin{array}{l}\text { Sulfato de } \\
\text { amônio } \\
\left(\text { g. }^{-1}\right)\end{array}$ & $\begin{array}{c}\text { Extrato de } \\
\text { Levedura }\left(\mathrm{g} . \mathrm{L}^{-1}\right)\end{array}$ & $\begin{array}{l}\text { Atividade } \\
\text { Máxima } \\
\left(\mathrm{U} . \mathrm{mL}^{-1}\right)\end{array}$ \\
\hline 1 & $-1(5,0)$ & $-1(1,0)$ & $-1(5,0)$ & $-1(0)$ & $-1(1,0)$ & $-1(1,0)$ & 1,6 \\
\hline 2 & $1(7,0)$ & $-1(1,0)$ & $-1(5,0)$ & $-1(0)$ & $1(5,0)$ & $-1(1,0)$ & 1,9 \\
\hline 3 & $-1(5,0)$ & $1(6,0)$ & $-1(5,0)$ & $-1(0)$ & $-1(1,0)$ & $1(5,0)$ & 2,9 \\
\hline 4 & $1(7,0)$ & $1(6,0)$ & $-1(5,0)$ & $-1(0)$ & $1(5,0)$ & $1(5,0)$ & 4,0 \\
\hline 5 & $-1(5,0)$ & $-1(1,0)$ & $1(20,0)$ & $-1(0)$ & $-1(1,0)$ & $1(5,0)$ & 3,6 \\
\hline 6 & $1(7,0)$ & $-1(1,0)$ & $1(20,0)$ & $-1(0)$ & $1(5,0)$ & $1(5,0)$ & 4,9 \\
\hline 7 & $-1(5,0)$ & $1(6,0)$ & $1(20,0)$ & $-1(0)$ & $-1(1,0)$ & $-1(1,0)$ & 4,7 \\
\hline 8 & $1(7,0)$ & $1(6,0)$ & $1(20,0)$ & $-1(0)$ & $1(5,0)$ & $-1(1,0)$ & 5,5 \\
\hline 9 & $-1(5,0)$ & $-1(1,0)$ & $-1(5,0)$ & $1(7,0)$ & $-1(1,0)$ & $1(5,0)$ & 1,7 \\
\hline 10 & $1(7,0)$ & $-1(1,0)$ & $-1(5,0)$ & $1(7,0)$ & $1(5,0)$ & $1(5,0)$ & 2,3 \\
\hline 11 & $-1(5,0)$ & $1(6,0)$ & $-1(5,0)$ & $1(7,0)$ & $-1(1,0)$ & $-1(1,0)$ & 1,1 \\
\hline 12 & $1(7,0)$ & $1(6,0)$ & $-1(5,0)$ & $1(7,0)$ & $1(5,0)$ & $-1(1,0)$ & 1,3 \\
\hline 13 & $-1(5,0)$ & $-1(1,0)$ & $1(20,0)$ & $1(7,0)$ & $-1(1,0)$ & $-1(1,0)$ & 1,9 \\
\hline 14 & $1(7,0)$ & $-1(1,0)$ & $1(20,0)$ & $1(7,0)$ & $1(5,0)$ & $-1(1,0)$ & 2,2 \\
\hline 15 & $-1(5,0)$ & $1(6,0)$ & $1(20,0)$ & $1(7,0)$ & $-1(1,0)$ & $1(5,0)$ & 2,3 \\
\hline 16 & $1(7,0)$ & $1(6,0)$ & $1(20,0)$ & $1(7,0)$ & $1(5,0)$ & $1(5,0)$ & 4,4 \\
\hline 17 & $0(6,0)$ & $0(3,5)$ & $0(12,5)$ & $0(3,5)$ & $0(3,0)$ & $0(3,0)$ & 3,5 \\
\hline 18 & $0(6,0)$ & $0(3,5)$ & $0(12,5)$ & $0(3,5)$ & $0(3,0)$ & $0(3,0)$ & 3,3 \\
\hline 19 & $0(6,0)$ & $0(3,5)$ & $0(12,5)$ & $0(3,5)$ & $0(3,0)$ & $0(3,0)$ & 3,3 \\
\hline 20 & $0(6,0)$ & $0(3,5)$ & $0(12,5)$ & $0(3,5)$ & $0(3,0)$ & $0(3,0)$ & 3,2 \\
\hline
\end{tabular}




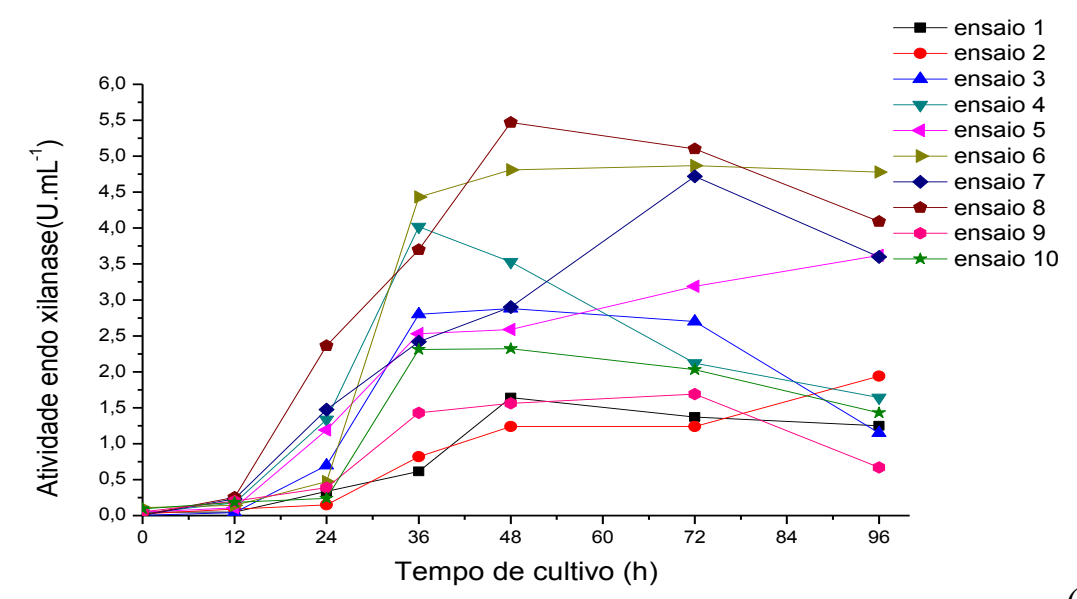

(a)

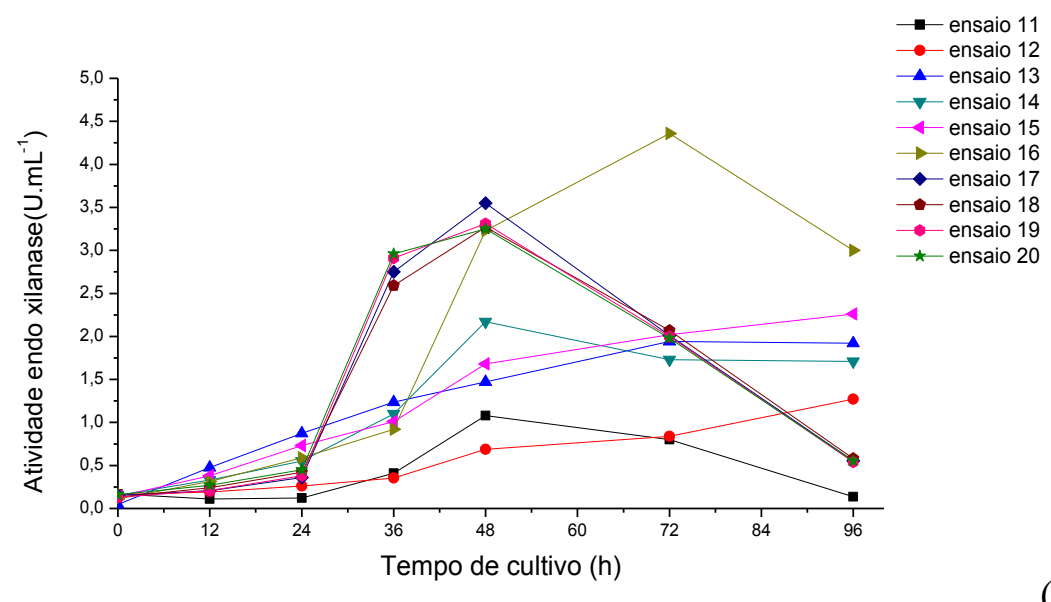

(b)

Figura 2: Acompanhamento da atividade enzimática ao longo do tempo, em diferentes ensaios realizados no planejamento fracionário em estudo. Sendoos ensaios de 1 a 10 (Fig. 2a) e ensaios de 11 a 20 (Fig. 2b)

Os resultados obtidos neste trabalho foram superiores aos descrito por Motta (2008), que isolou leveduras de diversas fontes ambientais a fim de selecionar aquelas com capacidade de produzir xilanases, sendo as cepas AY10 e AAD5, as mais promissoras. Após os autores avaliarem diferentes faixas de $\mathrm{pH}$ e temperatura, as atividades para endo xilanase foram de $2,53 \mu \mathrm{mol} / \mathrm{mL}$.min para a levedura AY10 e 3,24 $\mu \mathrm{mol} / \mathrm{mL}$.min para a levedura AAD5.

Pode-se observar pela figura 3 que das variáveis estatisticamente significativas que foram avaliadas, no presente trabalho, apenas a concentração de fosfato de potássio monobásico provocou um efeito negativo na atividade de endo xilanase, como seu nível mais baixo estudado foi a não adição desse sal, pode-se afirmar que o mesmo deve não deve estar presente no meio de cultura para que se possa atingir maiores atividades enzimáticas durante o cultivo. Todos os outros fatores avaliados (estatisticamente significativos) tiveram efeito positivo na resposta avaliada. 
A concentração de xilana foi a variável que mais afetou a resposta, sendo, portanto o fator mais importante dentre os avaliados no presente estudo para a produção da enzima de interesse. A indução de xilanase é normalmente estimulada pela xilana e também pode ser induzida por xilooligossacarídeos e xilose que são produzidos no meio pela própria enzima (Beg, 2001).

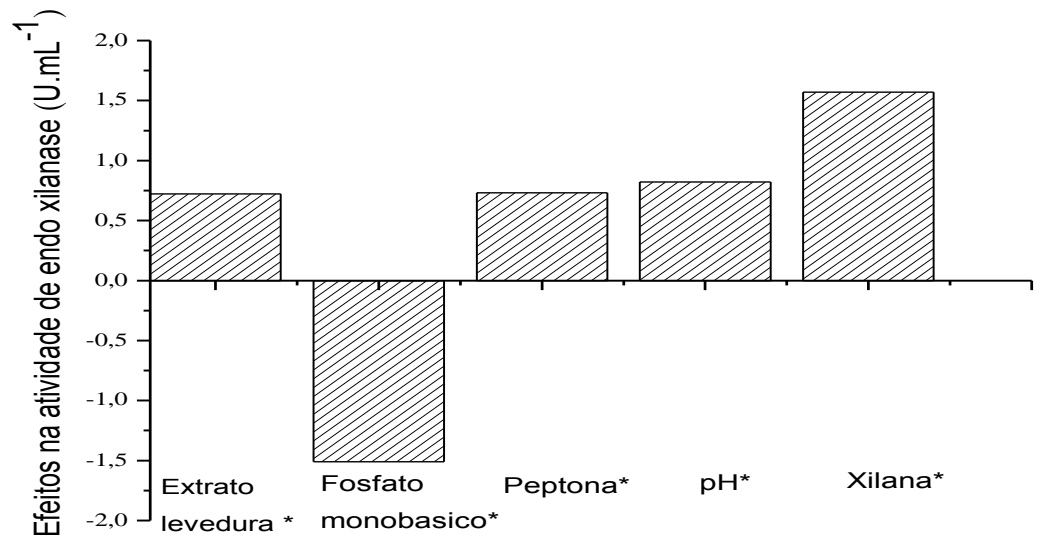

Figura 3: Gráfico de efeitos para as variáveis estudadas no planejamento fatorial $2^{6-2}$.

As variáveis $\mathrm{pH}$, concentração de extrato de levedura e concentração de peptona, tiveram efeito na mesma ordem de valores na atividade de endo xilanases produzidas no presente estudo. Com isso, pode-se afirmar que com a remoção do fosfato de potássio monobásico, maiores quantidades de xilana, peptona e extrato de levedura e $\mathrm{pH}$ em torno de 7, podem ser condições promissoras para a produção da enzima endo xilanase, sendo, portanto, de extremo interesse a avaliação de diferentes faixas de trabalho desses componentes para a maximização da produção enzimática. Quando a fermentação da xilana ocorre em substratos complexos e heterogêneos, vários fatores exercem um efeito conjunto no nível de expressão dessas enzimas. Em geral a indução da xilanase é um fenômeno complexo e o nível da resposta de um indutor varia de acordo com o microorganismo (Kulkarni et al, 1999). Geralmente esta enzima pode ter sua síntese associada a mudanças nutricionais e favorecidas pelas condições de cultivo (Angelo, 1995).

Em termos de produtividade o ensaio 8, o qual apresentou as maiores atividades ao longo do cultivo, teve sua maior produtividade $\left(0,11 \mathrm{U} . \mathrm{mL}^{-1} \mathrm{~h}^{-1}\right)$ em 48 horas de cultivo. Sua atividade teve um incremento de $69 \%$ quando a temperatura foi elevada de 50 a $55^{\circ} \mathrm{C} \mathrm{em} \mathrm{pH} \mathrm{5,3.}$

\section{CONCLUSÃO}


O uso do planejamento experimental permitiu verificar a influência do $\mathrm{pH}$, concentração de peptona, xilana, fosfato de potássio monobásico, sulfato de amônio e de extrato de levedura frente a atividade de endo xilanases produzida pela levedura Cryptococcus laurentii. Foram verificadas atividades enzimáticas superiores às encontradas com as condições originais de cultivo, onde através do planejamento foi possível aumentar em mais de $60 \%$ a atividade enzimática. O estudo também forneceu informações importantes para a maximização da produção de endo xilanases por Cryptococcus laurentii.

\section{AGRADEDIMENTOS}

A FAPERGS, CNPQ, CAPES pelo apoio financeiro.

\section{REFERÊNCIAS}

ANGELO R. S. Xilanases de Aspergillus sp. 2M1: produção, caracterização e aplicação no branqueamento de polpas Kraft. Dissertação de mestrado. Unicamp, Campinas, SP, 1995.

AOAC INTERNATIONAL. Official Methods of Analysis (OMA). 17. ed. AOAC International: Gaithersburg, 2000.

BAILEY, M. J.; BIELY, P.; POUTANEN, K. Interlaboratory testing of methods for assay of xylanase activity. J Biotechnol, v.23, p.257-270, 1992.

HALTRICH, D. et al. Production of fungal xylanases. Bioresource Technol, Kidlington, v.58, p.137-161, 1996.

HECK, J. X.; SOARES, L. H. B.; HERTZ, P. F.; AYUB, M. A Z. Purification and properties of a xylanase produced by Bacillus circulans BL53 on solid-state cultivation. Biochem Eng J, v.32, p.179-184, 2006.

JÄNIS, J.; PULKKINEN, P.; ROUVINEN, J.; VAINIOTALO, P. Determination of steady-state kinetic parameters for a xylanase-catalyzed hydrolysis of of neutral underivatized xylooligosaccharides by mass spectrometry. Anal Biochem, v.365, p.165-173, 2007. 
KULKARNI, P. P.; KADAM, A. J.; MANE, R. B.; DESAI, U. V.; WADGAONKAB, P. P. Demethylation of methyl aryl ethers using Pyridine hydrochloride in solvent-free conditions under microwave irradiation. J Chem Res-S, p.394- 395, 1999.

LI, Y.; CUI, F.; LIU, Z.; XU, Y.; ZHAO, H. Improvement of xylanase production by Penicillium oxalicum ZH -30 using response surface methodology. Enzyme Microb Tech, v.40, p.1381-1388, 2007.

LOPES, F.P. Otimização da produção de xilanase por levedura silvestre. Dissertação de mestrado. Faculdade de Engenharia de Alimentos, Universidade Estadual de Campinas, Campinas, 2010.

MILLER, G.L. Use of dinitrosalicylic acid reagent for determination of reducing sugar. Anal Chem, v.31, p. 426-428, 1959.

MOTTA, F. B. Triagem, seleção, produção e caracterização da enzima xilanase a partir de leveduras silvestres. Dissertação de mestrado. Faculdade de Engenharia de Alimentos, Universidade Estadual de Campinas, 2008.

OTERO, D. M.; TEIXEIRA, L. M.; SANZO, A. V.; KALIL, S. J. Selección de levaduras productoras de enzimas xilanoliticas. In: IV CONGRESO INTERNACIONAL DE CIENCIA Y TECNOLOGIA DE LOS ALIMENTOS,1, 2012, Cordoba. Anais IV Congreso Internacional de Ciencia y Tecnologia de los Alimentos: 2012.

RODRIGUES, M. I.; IEMMA, A.F.; Planejamento de experimentos e otimização de processos: uma estratégia seqüencial de planejamentos. $1^{\text {a }}$ Ed. Campinas - SP, 2005.

SUBRAMANIYAN,S.; SANDIA,G.S.;PREMA,P. Control of xylanase production without protease activity in Bacillus sp. By selection of nitrogen source. Biotecnol lett, v.23, p.369-371, 2001. 